\title{
The Narrative Consistency of the Warcraft Movie
}

\author{
Jonathan Barbara
}

Saint Martin's Institute of Higher Education, Malta

DOI: https://doi.org/10.7358/ijtl-2018-001-barb

jbarbara@gmail.com

ABSTRACT - The transmedial consumption of stories is dependent on disjoint experiences that exhibit coherence despite their medium differences. Coherence, however, is subjective and depends on the audience's prior exposure to other experiences in the transmedia franchise. This article presents an empirical study involving an online questionnaire with 106 participants worldwide on the narrative consistency of the Warcraft movie relative to the stories delivered through the many games, novels and comics in the franchise. Results show that the movie attracted narrative engagement from fans and non-fans alike. Fans judged it to be mostly cohesive in terms of storyworld, characters, and events which, the latter together with action, were the explanatory variables for the overall narrative consistency of the movie. Maintaining the sequence of events and their outcome, together with providing action consistent with the game's mechanics, is a good way to maintain narrative consistency in movies based on games, while allowing the medium to explore its full potential in the visualization of the storyworld and the portrayal of its characters.

\section{INTRODUCTION}

In the last decade, the use of multiple platforms to deliver one or more stories from the same storyworld to its audience has become a popular form of entertainment (Jenkins 2006), marketing (Buckner and Rutledge 2011), education (Lamb 2011) and organisational communication (Li 2013; von Stackelberg and Jones 2014). In the entertainment sphere, this has developed into two main production approaches: the so called West Coast or Hollywood model, where an initial blockbuster film is extended through sequels, novelizations and games with commercial benefit being the main objective; and the East Coast model where a single story is systematically dispersed across multiple narratives delivered through multiple platforms, focusing mostly on authorial objectives (Clark 2011; Phillips 2012, 13-14). 
However, the subjective critique of each single experience in a transmedia production is affected by the existence, length, and temporal distance of that particular audience's exposure to other experiences in the same storyworld (Dicieanu 2013, 14-15). Moreover, even if having seen none of the other experiences, and thus being freshly exposed to the storyworld through this particular experience, audiences adopt what MarieLaure Ryan calls the "principle of minimal departure" i.e. the reconstruction of a fictional world as being the closest possible to the reality known from their previous first-hand and second-hand experiences of the real (Ryan 1980, 405) and other fictitious worlds (418).

Thus, any empirical evaluation of an experience that is part of a transmedia production should be interpreted in the light of the evaluator's previous exposure to the storyworld which would fuel their expectations for the experience at hand. With such previous experiences being outside the control of the transmedia producers, empirical analysis of existing franchises could support theoretical models of transmedia storytelling design (Breum and Midtgaard 2013, 170; Thon 2016, 27-28) and assist in identifying critical areas which mandate a high level of coherency to meet audience expectations and others that allow for greater freedom and creativity in taking advantage of opportunities afforded by medium-specific features.

Using the filmic revisiting of the narrative of the first Warcraft video game Orcs and Humans (1994) into last year's Warcraft (2016) movie as an exemplar and the author's Narrative Consistency Scale (Barbara 2015) as an instrument, this study explores the narrative consistency of the movie with respect to its precursor games and novels.

This paper first argues in favour of the consideration of the audience's transmedial consumption of narratives. It then briefly covers the expansion of the Warcraft Universe over the past 22 years across multiple media platforms prior to the movie's release in order to understand what possible previous exposure a candidate audience of the Warcraft movie could have. The paper then uses Ryan's Narratological Approach to Transmedia Storytelling $(2016,8)$ and addresses its audience behaviour component through an empirical research study involving both experience-specific and transmedial $^{1}$ analysis of the movie with respect to earlier exposures to the fran-

${ }^{1}$ «transmedial» is used here as an adjective inferring an action or noun that transcends media. «Transmedia» is used to refer to the phenomenon of transmedia storytelling or production. 
chise. The paper then suggests some contributions this study can offer in the analysis of transmedia productions.

\section{TRANSMEDIAL CONSUMPTION OF NARRATIVES}

Today's audience, heralded by Henry Jenkins' aptly titled work "Convergence Culture" (2006), is no longer content with what is being delivered by the single medium, but seeks out other sources of information to help interpret and engage with the story, in order to satisfy its "transmedial desire" (Tosca 2015, 36). Like judges in a law court, the audience tries to build a coherent fictional truth based on the witness accounts provided by other media experiences in the same storyworld, or assumptions are made from real-life experiences if none are found to satisfy the need for knowledge (Ryan 1980, 405).

Whilst producers have taken advantage of this potential cross-selling opportunity whereby movie goers can be lured into buying, say, prequel novels and video game sequels, such as in the case of The Matrix (Krug and Frenk 2006), unfaithful adaptations, continuity errors, and reboots tend to attract anger from fans of the franchise such as the TV show Torchwood (Hills 2012). Indeed, according to Stam's “Intertextual Dialogism” (2000, 64), further expanded upon by Constantinides in his "Post-Celluloid Adaptation Theory" (2010), new narratives should provide an experience that is cohesive and consistent in order to support the fabula being shared between the narratives, especially in terms of storyworld, timeline of events, and characters (Breum and Midtgaard 2013). However, satisfying the fans may also be to the detriment of fidelity to the original text such as in The Lizzie Bennet Diaries, a YouTube series adaptation of Jane Austen's novel Pride and Prejudice, where the authors believed fans would find their emphasis on Austen's feminism appealing, and changed her characters to present feminism and romance in their modern form (Robbins 2016).

Meanwhile, depending on other media experiences to provide the narrative backbone may result in storyworlds feeling incomplete, as in the case of the now defunct transmedia production Defiance, involving Syfy channel and video game developers Trion Worlds (TV Series Defiance 2013). Both narratives deal with a post-apocalyptic world where humans and aliens coexist on a totally transformed earth due to alien terraforming technology. 
While the TV series followed some characters inhabiting the town of Defiance in what was St Louis in the state of Missouri, USA, the video game took place alongside the series in San Francisco Bay Area where players search for advanced alien technology through the remains of the war that took place 15 years earlier between the humans and the aliens.

However, reviews of the Defiance transmedia production had been directly on the experiences themselves and not on the transmedia production with critics unwilling to engage beyond their field of expertise giving the respective instalment bad reviews: the game reviewers had not followed the TV series and thus complained of lack of story and accused the gameworld of having no connective tissue, while reviews of the TV series failed to consider the online game extension, with none of the reviewers having played it. This was due to a general lack of holistic transmedia reviews that were initially called for by Geoffrey Long's white paper urging for "a robust system of transmedia criticism" (Long 2011,3).

The importance of the audience' s role in the success of a transmedia production was put to the fore in Ryan's narratological approach to transmedia storytelling wherein a Transmedia Franchise is decomposed into four parts : the transfictional, the mythical, the adaptive, and the audience behavior components (Ryan 2016, 8). This latter sociological component considers the transmedial success of the project in terms of the transmedial involvement of fans and standard audiences, and thus, together with Breum and Midtgaard $(2013,170)$ and Thon $(2016,27-28)$, invites empirical research in the area of transmedia storytelling user experience.

\subsection{Experience-specific Analysis}

In measuring a transmedial user experience, the experience in question affords assessment on its own merit as well as in relation to the other media experiences. Whilst this study is more interested in the transmedial dimension of the experience, the audience's engagement with the experience has a direct effect on their evaluation of its transmedial nature: if a film does not satisfy the expectations of a cinematic experience, there is a danger that this will bias their assessment of its transmedial nature. Also, in the case of films based on games, one is bound to ask whether the movie is engaging on its own merit or whether one needs to be acquainted with the lore (Ryan 2016, 7). 


\subsection{Transmedial Analysis}

In discussing the difficulties of a narratological approach to Transmedia Storytelling, Ryan suggests a "big data" approach due to the large volume and different nature of experiences making up such a production, because close reading, typical of literary studies, would require focusing on the relationship between a limited subset of the narratives involved (Ryan 2016, 7). In this relationship, narrative consistency, or forms thereof, has been deemed to be a critical success factor in transmedia storytelling by both media scholars (Jenkins 2003; Dena 2010; Dowd et al. 2013), and practitioners (Gomez 2012; Bernardo 2014). However the lack of a quantitative measure for such a criterion makes it difficult to judge the narrative consistency of a narrative with respect to other narratives in the same transmedia production (Jenkins 2006, 98 - 99).

An attempt to enable such a measurement was made through the design of the Narrative Consistency Scale (Barbara 2015) which starts from faithfulness to previously established canon in the form of Consistent narratives all the way down to Conflicting narratives. This five-stage linear scale decreases in consistency to a Cohesive level of narrative, where differences are justified through plausible causes such as in sequels, to Irrelevance, where new experiences have no impact on those already past - such as in spin-offs. Going further, Inconsistent narratives, such as those that employ retroactive continuity to alter previously set facts in order to allow for new plots, start failing expectations without contradicting directly the original knowledge, which happens in the Conflicting stage that is more attributable to parodies and reboots.

\subsection{Research aims}

This empirical study aims to contribute towards the corpus of close reading of transmedial productions by focusing on the relationship of one narrative, specifically the Warcraft movie released in 2016, with respect to the Warcraft lore as remembered by its fans.

The experience-specific analysis is carried out using the Narrative Engagement Model by Busselle and Bilandzic (2009) which measures four categories of narrative experience quantifying the audience's involvement with the story being told. 
For the transmedial analysis part, the Narrative Consistency Scale is being used to compare the transmedial nature of the Warcraft movie with its predecessor games, novels, and comics with respect to its narrative consistency.

\section{THE WARCRAFT UNIVERSE}

The Warcraft adventure begins with Blizzard's release of Orcs and Humans, a Real-Time Strategy (RTS) game in which the Orcs invade the Human world of Azeroth. The game was followed by sequels, with changes in game mechanics, from single player campaigns to massively multiplayer online role playing games, changing to a subscription model with World of Warcraft, that afforded a self-sustainable periodical release of expansions that is still ongoing.

The Warcraft story attracted renowned writers such as Richard Knaak, of Dragonlance fame, Christie Golden, from the Star Trek novels, and Jeff Grubb from Dungeons and Dragons. Thus, throughout the years, tens of licensed novels and comics tell stories happening before, during, and after the stories lived through the games, expanding the lore of the Warcraft Universe.

Blizzard also licensed a number of board games that mimicked the digital gameplay, a trading card game, a miniatures game, and themed versions of Monopoly and Trivial Pursuit.

Blizzard was also well known for its in-game cinematics, but the breakthrough came when Chris Metzen, then senior Vice President of Story and Franchise at Blizzard Entertainment, realised that "there's potentially a much wider audience receptive to Warcraft storytelling that is not necessarily [narrated] in a book" (Youtube Behind the Scenes of Lords of War-Story 2014). This led Blizzard to explore other media through which to tell their stories, such as with their particular motion story style of the animated shorts preceding the major expansions of World of Warcraft including Mists of Pandaria (Video Game 2012), Warlords of Draenor (Video Game 2014) and Legion (Video Game 2016).

Recently Blizzard variated its games provision while challenging wellknown stalwarts like Magic the Gathering and League of Legends by respectively releasing their own casual digital card game Hearthstone (2014) oriented in the world of Warcraft and Heroes of the Storm (2015), a shared 
universe game involving all the great heroes from Blizzard's three franchises: Warcraft, Starcraft, and Diablo. Thus, it is not a surprise that such an expansion process would see Metzen and his Blizzard team make the move into film, following it up with the novelization of the movie together with its prequels in novel and comic form.

\subsection{Conflict in the Warcraft Movie}

The story of Warcraft is quite complicated due to a dual timeline across two planets as a result of time travel in one of the expansions that messes up all the previous narratives. So it is no surprise that a third take on the story would result in a long list of conflicts as the movie's story replaces that told by the first RTS game in 1994, Orcs and Humans, with changes in the story and the characters ${ }^{2}$ whilst the movie's prequel novelisation Durotan (Golden 2016) is in direct conflict with another novel by the same author written ten years earlier: Rise of the Horde (Golden 2006).

\subsection{Critical Reception}

Reviews were highly critical of the movie, with ratings of $32 \%$ on MetaCrit$i c^{3}$ and $28 \%$ on Rottentomatoes ${ }^{4}$ whilst it did not recoup its $\$ 160$ million budget from its local box office gatherings of a little over $\$ 47$ million. But the audience ratings turned the tables: $76 \%$ on Rottentomatoes and $83 \%$ on MetaCritic, with \$386million gained from the box offices outside the United States. \$220million of these were from China only, where the movie was an instant hit, raking in $\$ 65$ million by the second day from its release ${ }^{5}$.

Tellingly, the negative criticism and the positive response were different perspectives on the same issues in the movie: the CGI effects, the main and secondary characters, the fact that it was a game-adaptation, and the ground-laying techniques used to prepare for the upcoming sequels.

${ }^{2}$ http://wow.gamepedia.com/Warcraft_film_universe

${ }^{3} \mathrm{http}: / /$ www.metacritic.com/movie/warcraft

${ }^{4}$ https://www.rottentomatoes.com/m/warcraft/

${ }^{5} \mathrm{http} / /$ www.boxofficemojo.com/movies/?page=intl\&view= bycountry\&id = warcraft.htm 


\subsection{Narratological Approach to Transmedia Storytelling in Warcraft}

However such issues are understandable if seen in the light of Ryan's narratological approach to Transmedia Storytelling (Ryan 2016, 8) mentioned earlier. The Transfictional component takes the form of Modification: as characters and events from the story exposed in the games and novels have been reinvented and redesigned. For example, the variation in the secondary character Orgrim Doomhammer's origins and fate lead to a different sequence of events in the eventual sequels.

The Adaptive component refers to changes in the story as a result of the employed medium. The movie introduces a horde of new characters that make the story feel more real - the King should have a Queen, and the hero of Azeroth ought to have a personal reason to take on Blackhand, the Orc Chieftain, so a son is given to him for the Chieftain to kill and attract his vengeful ire.

Warcraft further qualifies as a transmedia story through the mythical component being satisfied by the quasi-religious following of the Warcraft universe with its millions of subscribers who log-in daily, the thousands who attend the annual BlizzCon conference and the faithful cosplay activities around the world.

The fourth and final component leads to the scope of this research: the Audience Behavior component which addresses the audience's reaction to the transmedia franchise. Whether Warcraft is a transmedia franchise or not is irrelevant here as this study is not considering the transmedial design of the story but rather the transmedial consumption of the story by the majority of the audience who, willingly or not, have not consumed every narrative installment of the past and thus make a subjective judgement on the role of the movie within the Warcraft universe.

\section{Methodology}

This study involved a qualitative research using an online questionnaire delivered through Google Forms comprising of questions on (i) the participants' film viewing context (ii) their basic film rating (iii) their Narrative Engagement (iv) their experience of the Warcraft games and its other narratives, and (v) the Narrative Consistency of the movie with the games. 


\subsection{The Questionnaire}

Participants were asked when, where, and with whom they watched the movie in order to cater for variation in narrative engagement levels. They were then asked to rate on a 5-point Likert scale the film's story, visuals, and audio to measure how happy they were with the film. The Narrative Engagement Questionnaire then followed with 20 questions split into 4 categories: Emotional Engagement, Narrative Presence, Attentional Focus, and Narrative Understanding.

The participants were then asked if they had ever played any Warcraft game and, if so, were presented with a list of such games, together with novels and comics, in order to identify which ones they had played or read. They were also asked for the longest duration of this gameplay, in order to quantify their ludic engagement, and how long ago these games were last played, in order to measure how fresh their memory of the games' lore would be. This information is important because the temporal component of Transmedia Storytelling may have an impact on what the audience remembers of the story and what it will use to judge the movie in terms of narrative consistency (Harvey 2011, 279). They were then provided with a 5 -point Likert scale to agree or not with the statement that the film was consistent with the game and were then asked to indicate how much they felt to be fluent with the game's story.

The final section addressed another important question: Which criteria of the movie were considered to be the most important in judging its narrative consistency with the games?

To answer this question, participants were presented with the Narrative Consistency Scale, with each point on the scale being explained in one sentence and were then asked to rate the narrative consistency of each of the three narrative elements, namely storyworld, characters, and events. Because of the interactive origins of the story narratives that were the games, the "action" component was also introduced. Specifically, participants were then asked how they would rate two to four sub-elements of each criterion using the narrative consistency scale when compared with the original game.

Finally participants were given the opportunity to explain further any particular rating given and invited to provide their email address for further follow-up on their participation. 


\subsection{The Participants}

Participants were sought by posting a short invitation and a link to the questionnaire on social media, movie review sites, Warcraft's own forums on Battle.net, and on BoardGameGeek.com under the Warcraft board game fora. Invitations were also open to those who had watched the film without ever having played, or read, any Warcraft games or novels, resulting with a 9:1 ratio between fans and non-fans of the franchise.

In this empirical study where the interest lies in the transmedial consumption of a narrative, the participant's previous experience with the franchise determines whether the movie is perceived as an adaptation, or an optional irrelevant piece of narrative, or as a mandatory part of the grand narrative. This perception will then influence the expected peak of participant distribution along the Narrative Consistency scale from Consistent to Conflicting (see Table 1).

Table 1. Expected Peak Distribution based on perceived transmedial role

\begin{tabular}{|l|c|c|}
\hline Level & $\begin{array}{c}\text { Expected Peak Distribution } \\
\text { for }\end{array}$ & Skewness \\
\hline Consistent & Adaptations & $\mathrm{s}>1$ \\
\hline Cohesive & Top-Down Native Transmedia & $0.5<\mathrm{s}<1$ \\
\hline Irrelevant & $\begin{array}{c}\text { Bottom-up Adaptive } \\
\text { Transmedia }\end{array}$ & $\approx 0$ \\
\hline Inconsistent & Re-makes & $-0.5>\mathrm{s}>-1$ \\
\hline Conflicting & Parodies & $\mathrm{s}<-1$ \\
\hline
\end{tabular}

\section{RESUlTS}

In this study, 103 participants were found from at least 17 countries across the world, $58 \%$ of which were European. There were no participants from China but given the extreme popularity of the movie there, it is argued that China merits a separate study just for itself.

For experience-specific analysis, film rating in terms of story, visuals, and audio was compared with Narrative Engagement, resulting in a moderately positive Spearman correlation (see Table 2). 
Table 2. Spearman Correlation between Rating and Narrative Engagement criteria

\begin{tabular}{|l|c|c|c|}
\hline $\begin{array}{l}\text { Narrative Engagement } \\
\text { Criteria }\end{array}$ & $\begin{array}{c}\text { Story } \\
\text { Rating }\end{array}$ & p-value & $\begin{array}{c}\text { Spearman } \\
\text { correlation }\end{array}$ \\
\hline $\begin{array}{l}\text { Narrative Understanding } \\
\text { (Reverse Coded) }\end{array}$ & -0.491 & $<0.0001$ & moderate \\
\hline $\begin{array}{l}\text { Attentional Focus } \\
\text { (Reverse Coded) }\end{array}$ & -0.476 & $<0.0001$ & moderate \\
\hline Narrative Presence & 0.551 & $<0.0001$ & moderate \\
\hline Emotional Engagement & 0.465 & $<0.0001$ & moderate \\
\hline
\end{tabular}

The 93 participants who claimed to have played Warcraft in the past, hereon referred to as fans, scored Narrative Engagement on a 5-point Likert scale, with substantial Emotional Engagement but reduced Attentional Focus (see Figure 1). Conversely, non-fans of the franchise fared better in all criteria, with Narrative Understanding rating a high $74 \%$.

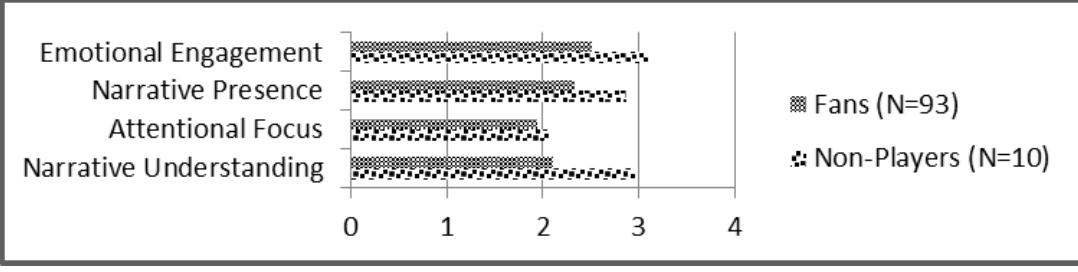

Figure 1. Narrative Engagement for the Warcraft Movie

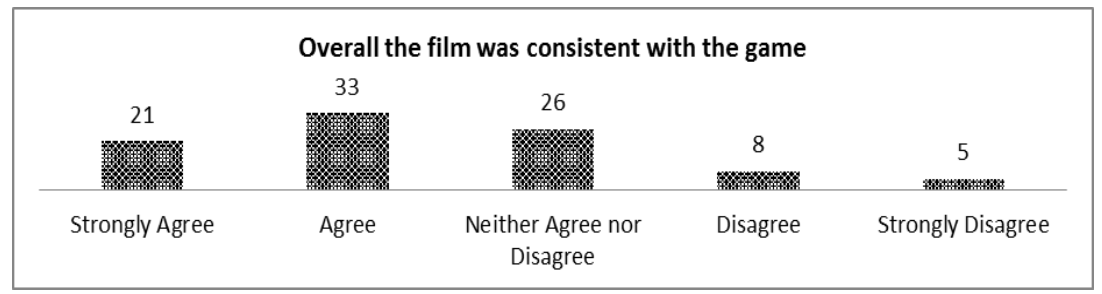

Figure 2. Overall consistency of the Warcraft movie as reported by the 93 fans 
Although there were so many inconsistencies between the canon, as delivered in the games and novels, and the movie, only $14 \%(\mathrm{~N}=13)$ perceived such inconsistencies (see Fig. 2). 22.6\% of the participants $(\mathrm{N}=21)$ found the film to be consistent while just over $35 \%(\mathrm{~N}=33)$ accepted the differences as justified, labelling the film as cohesive, and $28 \%$ found it to be irrelevant $(\mathrm{N}=26)$.

For the fans, there was a positive Spearman correlation between their rating of the movie's story, visuals, and audio with respect to the general perceived level of consistency with the games' lore (see Table 3). Overall consistency showed a strong correlation with the story rating while consistency of the landscape had a moderate positive correlation with the visuals, with colours and other visual elements only having a weak correlation. Consistency of sound effects and music had a moderate correlation with music and sound rating.

Table 3. Spearman Correlation between Rating and Consistency ( $N=93)$

\begin{tabular}{|l|c|c|c|c|c|}
\hline Consistency & $\begin{array}{c}\text { Rating } \\
\text { Story }\end{array}$ & Visuals & $\begin{array}{c}\text { Music and } \\
\text { Sound }\end{array}$ & p-value & $\begin{array}{c}\text { Spearman } \\
\text { correlation }\end{array}$ \\
\hline \begin{tabular}{l|c|c|c|c|c|}
\hline Overall \\
$\begin{array}{l}\text { Visual } \\
\text { Elements }\end{array}$
\end{tabular} & 0.614 & & & $<0.0001$ & Strong \\
\hline \begin{tabular}{l} 
Landscape \\
\hline Colours
\end{tabular} & & 0.352 & & 0.0004 & Weak \\
\hline $\begin{array}{l}\text { Sound } \\
\text { Effects }\end{array}$ & 0.429 & & $<0.0001$ & Moderate \\
\hline Music & & 0.287 & & 0.004 & Weak \\
\hline
\end{tabular}

The fans' previous experience with the Warcraft franchise of video games, board games, novels, and comics, shows that most fans were Warcraft III and World of Warcraft players with a good number of players that had played the original games and similar numbers had read the novels, while very few had read the comics and fewer still had played the board games (see Table 4) with the majority having played for more than a year and half of them having played as recently as the previous week. 
Table 4. Previous participant Warcraft experience as a percentage of the 93 fans, by category

\begin{tabular}{|c|c|c|}
\hline CATEGORY & Including & POPULARITY \\
\hline $\begin{array}{l}\text { BOARD \& } \\
\text { CARD }\end{array}$ & $\begin{array}{l}\text { Board games, miniatures, } \\
\text { trading card and Hearthstone }\end{array}$ & $15 \%$ \\
\hline COMICS & Manga and Warcraft Magazine & $14 \%$ \\
\hline MMORPG & World of Warcraft and Expansions & $65 \%$ \\
\hline MOBA & Warcraft III and Heroes of the Storm & $70 \%$ \\
\hline NOVEL & Warcraft and World of Warcraft Novels & $38 \%$ \\
\hline RTS & The original Warcraft and Warcraft II & $34 \%$ \\
\hline
\end{tabular}

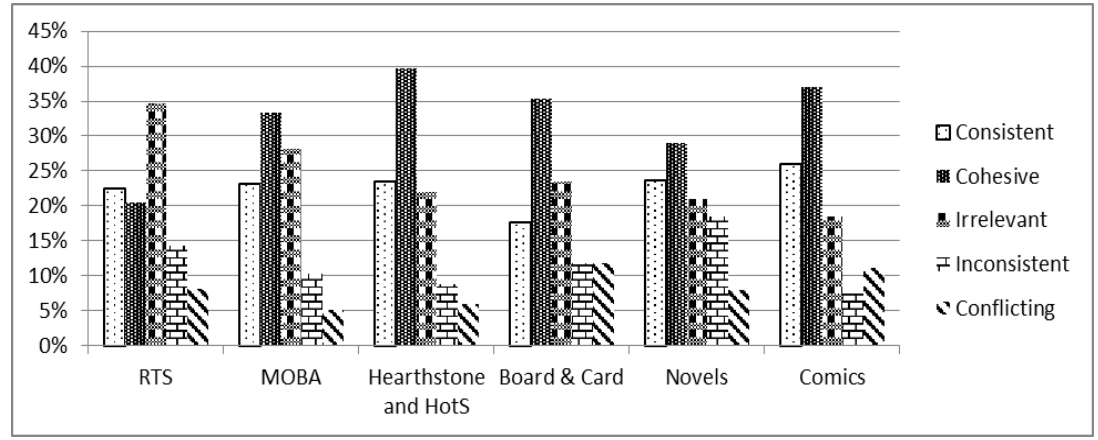

Figure 3. Narrative Consistency by Experience ( $\mathrm{N}=93)$

Analysing the narrative consistency based on experience by category (see Figure 3) reveals that the ones mostly pointing at inconsistencies in the movie were those who read the novels and those who played the first games - which are the ones telling the movie's story differently. The original RTS game players are also the ones mostly marking the movie as being irrelevant (see Figure 4). This distribution fits in with the bottom-up adaptive transmedia model in Table 1 where different experiences are tacked onto each other to play out different stories in the same storyworld.

On the other hand, those that did not play the original game Orcs and Humans have a positively skewed distribution with minimal outliers that 
centres on the cohesive rating, fitting with the top-down native transmedia model as the film is seen as a missing piece of the grand narrative, having missed the game's version of the story. Indeed, Hearthstone and Heroes of the Storm players, who are used to accessing the Warcraft universe through different game mechanics, found the movie mostly cohesive. Likewise did those who read Warcraft comics, possibly the visual style of the comics attracting judgement of similarity to the movie. This group in fact was the one which most voted the movie as being consistent.

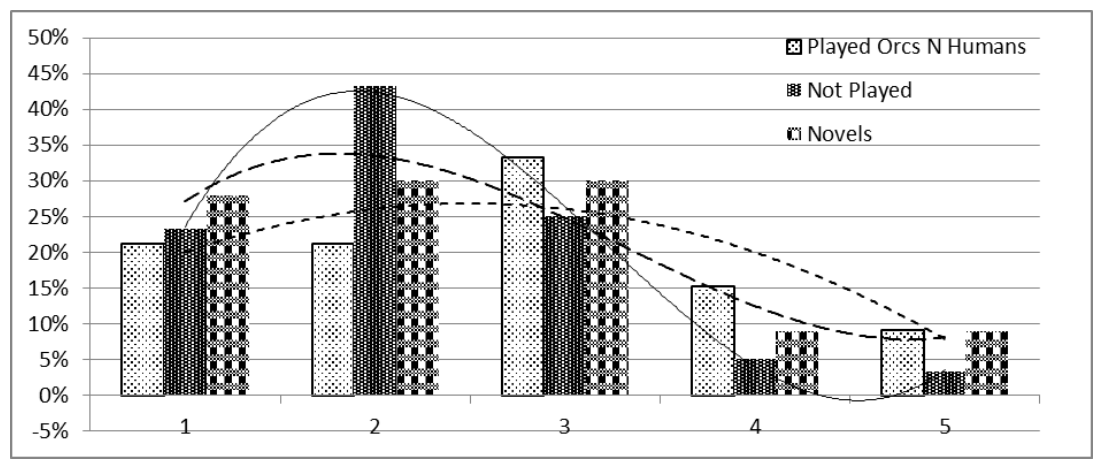

Figure 4. Population Distribution based on Previous Experience (N=93)

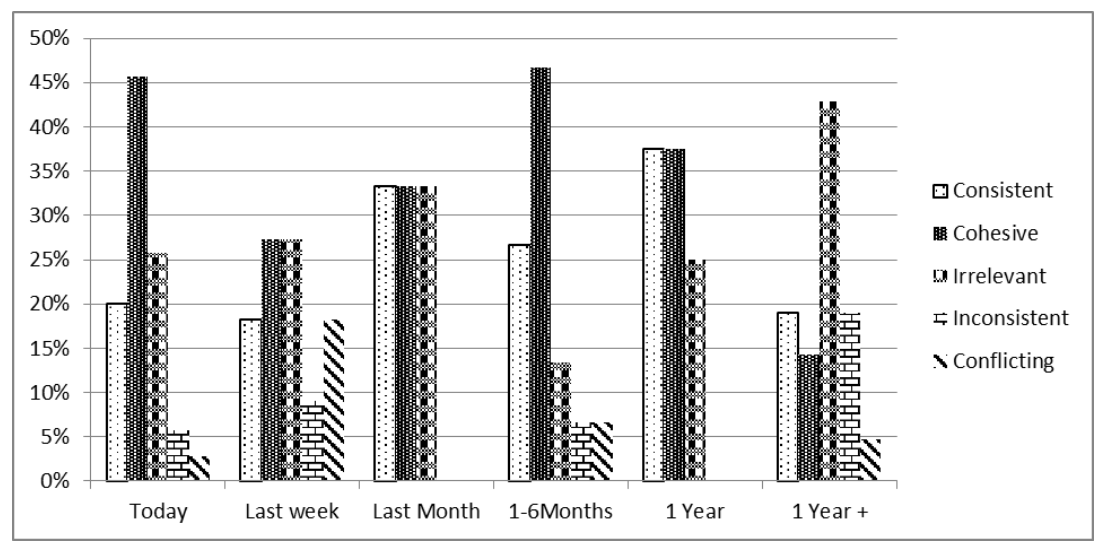

Figure 5. Narrative Consistency by Temporal Distance (N=93)

International Journal of Transmedia Literacy - 4 - December 2018

http: //www.ledonline.it/transmedialiteracy - Online ISSN 2465-2261 - Print ISSN 2465-227X 
The freshest memories led to perception of cohesion whilst those played last week felt it less cohesive and more conflicting. The further away was the experience the less cohesive and the higher the irrelevance of the movie experience (see Figure 5).

The more time was spent playing the games the more varied were the answers given, with some elements of inconsistency being felt. On the other hand, the less time spent playing the game, the less relevant the movie was perceived to be (see Figure 6).

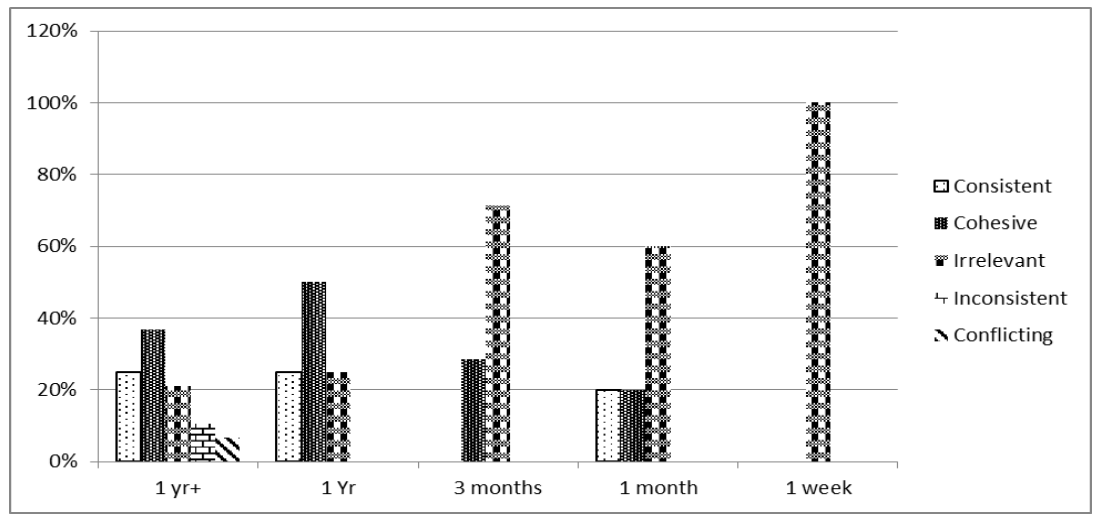

Figure 6. Narrative Consistency by Duration (N=93)

In the final section, the fans used the Narrative Consistency scale on a range of 1 (Consistent) to 5 (Conflicting) to rate sub-elements of the four Narrative elements of Storyworld (SW), Action (A), Characters (C) and Events (E) in comparison with their own memory of the Warcraft canon (see Table 5). Whilst overall scale analysis was high $(\alpha=0.92)$, scores for highest levels of narrative consistency were noted for the Storyworld element (Avg 1.77) with colour used in the film (SW3) being rated 1.54, midpoint between Consistent (1.0) and Cohesive (2.0). The least consistent was found to be the Events element (Avg 2.37) with the outcomes (E3) rating 2.40, between Cohesive (2.0) and Irrelevant (3.0).

Since normal distribution cannot be assumed given the varied audience exposure to the other narratives, Spearman correlation was used to correlate scores between the four elements and the overall value, with a moderate positive correlation being achieved individually with Events, Characters, and Actions (see tab. Table 6). 
Table 5. Average rating per question ( $S W=$ Story World, $A=$ Action, $C=$ Characters, $E=$ Events)

\begin{tabular}{|c|c|c|}
\hline CODE & QUESTION & AVG \\
\hline SW1 & $\begin{array}{l}\text { How would you rate the visual elements of the film in } \\
\text { comparison with the original game? }\end{array}$ & 1.66 \\
\hline SW2 & $\begin{array}{l}\text { How would you rate the landscape of the film in comparison } \\
\text { with the original game? }\end{array}$ & 1.69 \\
\hline SW3 & $\begin{array}{l}\text { How would you rate the colours used in the film in } \\
\text { comparison with the original game? }\end{array}$ & 1.54 \\
\hline SW4 & $\begin{array}{l}\text { How would you rate the sound effects used in the film in } \\
\text { comparison with the original game? }\end{array}$ & 1.78 \\
\hline SW5 & $\begin{array}{l}\text { How would you rate the music used in the film in comparison } \\
\text { with the original game? }\end{array}$ & 2.19 \\
\hline A1 & $\begin{array}{l}\text { How would you rate the actions in the film in comparison } \\
\text { with the original game? }\end{array}$ & 2.19 \\
\hline $\mathrm{C} 1$ & $\begin{array}{l}\text { How would you rate the appearance of the main character(s) } \\
\text { in the film in comparison with the original game? }\end{array}$ & 2.11 \\
\hline $\mathrm{C} 2$ & $\begin{array}{l}\text { How would you rate the tone of voice of the main } \\
\text { character(s) in the film in comparison with the original game? }\end{array}$ & 2.24 \\
\hline C3 & $\begin{array}{l}\text { How would you rate the behaviour of the main character(s) in } \\
\text { the film in comparison with the original game? }\end{array}$ & 2.22 \\
\hline $\mathrm{C} 4$ & $\begin{array}{l}\text { How would you rate the secondary character(s) in the film in } \\
\text { comparison with the original game? }\end{array}$ & 2.36 \\
\hline E1 & $\begin{array}{l}\text { How would you rate the events happening in the film in } \\
\text { comparison with the original game? }\end{array}$ & 2.41 \\
\hline E2 & $\begin{array}{l}\text { How would you rate the chronological/temporal/sequential } \\
\text { ordering of the events happening in the film in comparison } \\
\text { with the original game? }\end{array}$ & 2.32 \\
\hline E3 & $\begin{array}{l}\text { How would you rate the outcome of the events happening } \\
\text { in the film in comparison with the original game? }\end{array}$ & 2.40 \\
\hline
\end{tabular}

Table 6. Overall Narrative Consistency vs Narrative Element

\begin{tabular}{|l|c|c|c|c|}
\hline Element & $\begin{array}{c}\text { Avg } \\
\text { Rating }\end{array}$ & $\begin{array}{c}\text { Spearman } \\
\text { Correlation }\end{array}$ & $\begin{array}{c}\text { Regression } \\
\text { Analysis \#1 }\end{array}$ & $\begin{array}{c}\text { Regression } \\
\text { Analysis \#2 }\end{array}$ \\
\hline Storyworld & 1.77 & 0.35 & $-0.079(\mathrm{p}=0.678)$ & \\
\hline Events & 2.37 & 0.52 & $0.285(\mathrm{p}=0.023)$ & $0.383(\mathrm{p}=0.001)$ \\
\hline Characters & 2.23 & 0.5 & $0.252(\mathrm{p}=0.08)$ & \\
\hline Actions & 2.19 & 0.48 & $0.233(\mathrm{p}=0.039)$ & $0.297(\mathrm{p}=0.003)$ \\
\hline
\end{tabular}


An initial linear regression of the four elements proved significant for Events and Actions with coefficients 0.285 and 0.233 respectively and an adjusted $R$ squared value of 0.39 with a positive intercept of 0.8 . A second linear regression on just Events and Actions resulted with the following equation for the model explaining Narrative Consistency in terms of its explanatory variables:

$$
\text { Narrative Consistenc } y=0.86+0.297 * \text { Action }+0.383 * \text { Events }
$$

Due to the story's origins in games, which, unlike the passive reception of a movie narrative, are interactive by nature and thus afford agency for the player, the participants were asked what they understood by the word ' $a c$ tion' when asked to compare it between the movie and the game. The various responses given could be grouped into three main themes: A few referred to the visual depiction of action: the orcs' movement and their behaviour in battles. Others compared action to the narrative milestones in the story: major plot points and conflicts happening within the narrative, whilst others interpreted action as referring to the character behaviour in response to situations. Overall, Action was given an average rating of 2.19, close to being Cohesive (2.0).

\section{CRITICAL NARRATIVE ELEMENTS FOR COHERENCY IN TRANSMEDIA STORYTELLING: AN AUDIENCE PERSPECTIVE}

The analysis of a transmedia production has so far been either poorly served by biased reviews of individual experiences, such as evidenced by the low ratings on popular review sites such as MetaCritic and Rottentomatoes, or by academic studies, such as those of Gambarato (2013), that provide analytical evaluation of its design rather than empirical evaluation of its reception - with the latter being further suggested by Lemke in view of the complexity and volume of such transmedia productions, as well as the power of the fan community (Lemke 2010, 589).

Theoretical models (Breum and Midtgaard 2013) and practitioners (Dowd et al. 2013, 69) suggest coherency across the narrative dimensions of storyworld, events, and characters while recommending empirical analysis. Thus this paper investigated the impact of the narrative consistency, with 
established lore, of such elements on the perceived overall consistency of a narrative by using the Warcraft movie based on Blizzard Entertainment's franchise of the same name as a case study.

This is useful as it sheds light on how transmedia designers can identify what elements are perceived to be critical in measuring the integrity of a transmedial story and which allow for media-specific variations without jeopardising coherency and angering the fans. While Breum and Midtgaard $(2013,157)$ suggest a coherent Storyworld element with some freedom with Events and Characters when extending a narrative through a game, such as that of the Hunger Games, this research gave empirical results suggesting that Events and Characters have a significant impact on the perceived overall consistency of a movie based on a canon established mainly by games. The "principle of charity" attributed by Jan-Nöel Thon to players accepting inconsistencies between cinematics and gameplay in the same game (Thon 2016, 21-26) was extended to the transmedial experience perspective on the Warcraft movie as inconsistencies have been deemed to be majorly cohesive, justifying them through the needs of the cinematic medium.

This study has also demonstrated the use of the Narrative Consistency scale (Barbara 2017) through an online questionnaire that can be scaled out geographically to gather subjective opinions reflecting the audience's perception of a transmedial storytelling component. This questionnaire provides a repeatable manner of collecting data that is useful both for franchise-specific analysis as well as for a more general analysis of transmedia storytelling reception, to which this study is a candidate contribution. It exemplifies a data acquisition tool that enhances transmedia literacy skills through competence in its application to a target franchise and knowledge in its analysis of gathered data.

\subsection{Interpretation of Results}

The results show that the Warcraft movie can stand on its own as it was found to be narratively engaging even by those who had never played any of the games nor read any novels in the franchise, one of the criteria required for a transmedia story. Non-fans' higher rating for narrative understanding could possibly be due to the fans themselves being confused with perceived lore inconsistencies, but it may also be that the larger number of fans (93) provides a more averaged result compared to the 10 non-fan participants. 
Furthermore, the fans of the franchise found the movie to be mostly consistent $(22.6 \%)$ or cohesive $(35.5 \%)$ with the canon. Not having provided respondents with a possibility to abstain, the $28 \%$ who scored the film as irrelevant may include those who did not want to commit to either of the two polarities. Future uses of the Narrative Consistency scale ought to include such an option in order to eliminate such possible contamination.

Finally, the overall consistency ratings had a moderate correlation with scores for characters, events, and actions. Linear regression showed that $37 \%$ of the variability of the Narrative Consistency is explained by the Action and Events variables and with a significance level of $5 \%$, the information brought by the explanatory variables is significantly better than what a basic mean would bring $(\mathrm{p}<0.0001)$. Based on the Type III sum of squares, Action and Events bring significant information to explain the variability of Narrative Consistency, with Events being the most influential.

As a result of clarifications made by respondents, future studies ought to decompose the action element into its sub-elements of visual-depiction of action, narrative milestones, and character behaviour in response to situations.

\subsection{Future Work}

The subjective nature of the research as well as the future line-up of movies based on games being released in cinemas encourages further research based on the same methodology in order to increase the corpus of close readings of such transmedial narratives which will allow further generalisation of the narrative consistency model. This is especially attractive since movies based on games never fare better than $50 \%$ with movie critics. Furthermore, a similar approach can be taken with games that are based on movies in a typical West Coast transmedia model approach, or that are a mandatory part of a transmedia story as in the East Coast model. The broader the scope of analysis, in terms of franchise, media, and audience, the more contributory data can be gathered that can assist in developing a heuristic model that can help transmedia producers determine where consistency is critical and where it is malleable. 


\section{CONCLUSION}

This study contributes to the empirical analysis of transmedia storytelling using a questionnaire that assesses experience-specific narrative engagement and transmedial analysis of narrative consistency. In doing so, it provides a fan-driven close reading of the cinematic extension of one of the most popular franchises, Warcraft from Blizzard Entertainment.

The results of this study show that the movie itself was narratively engaging even for non-fans while fans found it to be mostly cohesive even if some inconsistencies were found in the outcome of events. Breaking down the narrative into its storyworld, characters, events and action elements, it was found that the narrative consistency levels of actions and events were the most influential on the overall perceived narrative consistency.

In conclusion, movie extensions of game narratives should provide action that reflects gameplay and portray a sequence of events that is consistent with audience expectation developed from exposure to the other experiences in the franchise whilst medium-specific features such as visual spectacles and characterization offer opportunities for creativity and variation.

\section{REFERENCES}

Barbara, Jonathan. 2015 "Towards Measuring Consistency Across Transmedial Narratives". In Interactive Storytelling, edited by Henrik Schoenau-Fog, Luis Emilio Bruni, Sandy Louchart, e Sarune Baceviciute, 243-50. Lecture Notes in Computer Science. Springer International Publishing.

Bernardo, Nuno. 2014. Transmedia 2.0. $1^{\text {st }}$ ed. London: beActive.

Breum, Annette Corpuz and Hanna Skov Midtgaard. 2013. "Story Bridges in Transmedia". Master Thesis, Aalborg, Denmark: Aalborg University. http://projekter.aau.dk/projekter/files/76985978/Story_Bridges_in_Transm edia_Midtgaard_Breum.pdf.

Buckner, Bonnie and Pamela Rutledge. 2011. "Transmedia Storytelling for Marketing and Branding: It Is Not Entertainment. It Is Survival”. International Marketing Association.

http://www.kcommhtml.com/ima/2011_03/transmedia_storytelling.

Busselle, Rick and Helena Bilandzic. 2009. "Measuring Narrative Engagement". Media Psychology 12 (4): 321-47. doi:10.1080/15213260903287259. 
Clark, Brian. 2011. "Reclaiming Transmedia Storyteller". May 2. https://www. facebook.com/notes/brian-clark/recriminare-transmedia-storyteller/101502 46236508993/.

Constandinides, Costas. 2010. From Film Adaptation to Post-Celluloid Adaptation: Rethinking the Transition of Popular Narratives and Characters across Old and New Media. Bloomsbury Publishing USA.

Dena, Christy. 2009. "Transmedia Practice: Theorising the Practice of Expressing a Fictional World across Distinct Media and Environments". University of Sydney. http://elmcip.net/critical-writing/transmedia-practice-theorisingpractice-expressing-fictional-world-across-distinct.

Dicieanu, Maria. 2013. “Adaptations: Primitive Transmedia Narratives?” In Crossing Channels, Crossing Realms: Immersive Worlds and Transmedia Narratives, Ed. Natalie Krikowa and Shawn Edrei, e-book. Oxford: Inter-Disciplinary Press. https://www.inter-disciplinary.net/critical-issues/wp-content/ uploads/2012/10/dicieanutmpaper.pdf.

Dowd, Tom, Michael Niederman, Micheal Fry and Joseph Steiff. 2013. Storytelling Across Worlds: Transmedia for Creatives and Producers. Waltham: Focal Press.

Gambarato, Renira Rampazzo, and others. 2013. "Transmedia Project Design: Theoretical and Analytical Considerations”. Baltic Screen Media Review, no. 1: 80100. http://publications.tlu.ee/index.php/bsmr/article/download/153/pdf.

Golden, Christie. 2006. Rise of the Horde. New York: Pocket Star.

Golden, Christie. 2016. Warcraft: Durotan. London: Titan Books.

Gomez, Berta. 2012. “A Humanistic-Geek Approach to Transmedia Storytelling: Transforming Users into Heroes and Authors to Build a Sustainable Universe". http://www.diva-portal.org/smash/record.jsf?pid=diva2:654085.

Harvey, Colin. 2011. “A Taxonomy Of Transmedia Storytelling”. In Storyworlds Across Media'conference, Johannes Gutenberg-University Mainz.

Hills, Matt. 2012. "Torchwood's Trans-Transmedia: Media Tie-Ins and Brand 'fanagement'”. Participations 9 (2): 409-428.

http://www.participations.org/Volume\%209/Issue\%202/23\%20Hills.pdf.

Jenkins, Henry. 2003. “Transmedia Storytelling”. MIT Technology Review. January 15. http://www.technologyreview.com/news/401760/transmedia-storytelling/.

Jenkins, Henry. 2006. Convergence Culture: Where Old and New Media Collide. New York: NYU press.

Krug, Christian, and Joachim Frenk. 2006. "Enter the Matrix-Interactivity and the Logic of Digital Capitalism”. Critical Studies 29 (1): 73-93. doi: 10.1163/ 9789401201292_005. 
Lamb, Annette. 2011. "Reading Redefined for a Transmedia Universe". Learning \& Leading with Technology 39 (3): 12-17. http://files.eric.ed.gov/fulltext/ EJ954320.pdf.

Lemke, Jay. 2010. "Transmedia Traversals: Marketing Meaning and Identity". In Interdisciplinary Perspectives on Multimodality: Theory and Practice. Proceedings of the Third International Conference on Multimodality. Campobasso: Palladino.

Li, Zhan. 2013. "A Canticle for Mary Sue: What Transmedia Aesthetics Might Do for Futures Communication”. Journal of Futures Studies 17 (3): 137-140. http://www.jfs.tku.edu.tw/17-3/S09.pdf.

Long, Geoffrey. 2011. "How to Ride a Lion: A Call for a Higher Transmedia Criticism". Massachusetts: MIT. http://www.convergenceculture.org/research/ c3-transmediacriticism-full-public.pdf.

Phillips, Andrea. 2012. A Creator's Guide to Transmedia Storytelling: How to Captivate and Engage Audiences across Multiple Platforms. McGraw Hill Professional.

Robbins, Shaina Gwynn. 2016. "Faithful to the Fans: Audience Influence on The Lizzie Bennet Diaries and Transmedia Adaptation Fidelity". http://scholars archive.byu.edu/etd/5823/.

Ryan, Marie-Laure. 1980. "Fiction, Non-Factuals, and the Principle of Minimal Departure". Poetics 9 (4): 403-422.

Ryan, Marie-Laure. 2016. "Transmedia Narratology and Transmedia Storytelling". Artnodes, no. 18.

Stackelberg, Peter von, and Ruth Eira Jones. 2014. "Tales of Our Tomorrows: Transmedia Storytelling and Communicating about the Future". Journal of Futures Studies 18 (3): 57-76. http://www.jfs.tku.edu.tw/18-3/A05.pdf.

Stam, Robert. 2000. "Beyond Fidelity: The Dialogics of Adaptation". Film Adaptation, 54-76.

Thon, Jan-Noël. 2016. "Narrative Comprehension and Video Game Storyworlds". Video Games and the Mind: Essays on Cognition, Affect and Emotion, 15.

Tosca, Susana. 2015. "We Have Always Wanted More". International Journal of Transmedia Literacy (IJTL) 1 (1): 35-43. doi: 10.7358/ijtl-2015-001-tosc.

\section{LIST OF CITED AUDIO VISUAL MEDIA}

Behind the Scenes of Lords of War - Story. 2014. Produced by Blizzard Entertainment. Youtube. https://www.youtube.com/watch?v=Pldi4gzQ15A.

Defiance. 2013 - 2015. Produced by Five \& Dime Productions. TV Series. 
Warcraft: Orcs and Humans. 1994. Published by Blizzard Entertainment. Video Game.

Warcraft: The Beginning. 2016. Directed by Duncan Jones. Universal Pictures. Film. Hearthstone. 2014. Published by Blizzard Entertainment. Video Game.

Heroes of the Storm. 2015. Published by Blizzard Entertainment. Video Game.

World of Warcraft: Legion. 2016. Published by Blizzard Entertainment. Video Game.

World of Warcraft: Mists of Pandaria. 2012. Published by Blizzard Entertainment. Video Game.

World of Warcraft: Warlords of Draenor. 2014. Published by Blizzard Entertainment. Video Game. 
